\title{
Cytotypic Differences in the Protein Composition of the Axonally Transported Cytoskeleton in Mammalian Neurons
}

\author{
Monica M. Oblinger, ${ }^{1}$ Scott T. Brady, ${ }^{1, a}$ Irvine G. McQuarrie, ${ }^{1,2}$ and Raymond J. Lasek ${ }^{3}$ \\ 'Department of Developmental Genetics and Anatomy, and 'Division of Neurosurgery, and ${ }^{3}$ Bioarchitectonics Center, \\ Case Western Reserve University School of Medicine, Cleveland, Ohio 44106
}

\begin{abstract}
Many of the structural and functional differences between axons are thought to reflect underlying differences in the biochemical composition and dynamic aspects of the axonal cytoskeleton and cytomatrix. In this study we investigated how the composition of the 2 slow components of axonal transport, $\mathrm{SCa}$ and $\mathrm{SCb}$, which convey the cytoskeleton and cytomatrix, differs in axons that are structurally and functionally distinct. For this comparison we analyzed axons of retinal ganglion cells in the optic nerve (ON), axons of dorsal root ganglion (DRG) cells, and axons of ventral motor neurons (VMN) in adult rats. ${ }^{35} S$-Methionine-labeled proteins transported with the peak of $\mathrm{SCa}$ and $\mathrm{SCb}$ were analyzed using high-resolution 2-dimensional polyacrylamide gels (2D-PAGE) and fluorography, and the amounts of major SCa and SCb proteins were quantified. The polypeptide composition of both $\mathrm{SCa}$ and $\mathrm{SCb}$ was found to be largely similar in DRG and VMN axons, but major qualitative as well as quantitative differences between these axons and $O N$ axons were found. Notable among these were higher ratios of neurofilament protein to tubulin in $\mathrm{SCa}$ in DRG and VMN axons compared to ON axons, and significantly larger amounts of $\mathbf{2}$ microtubule-associated proteins relative to tubulin in SCa of ON axons than in both VMN and DRG axons. Tubulin was the major SCb protein in VMN and DRG axons, but it was not present in SCb in ON axons. Additionally, relatively larger amounts of 2 metabolic enzymes, creatine phosphokinase and nerve-specific enolase, were present in SCb in ON axons than in DRG or VMN axons. The results indicate that significant biochemical heterogeneity among different types of axons can be identified by examining the slow components of axonal transport.
\end{abstract}

One of the hallmarks of the nervous system is the extreme diversity in the basic forms and functions of neurons. A longstanding assumption has been that the heterogeneity of neurons is at least partly a result of differences in the biochemical composition of different neurons. The complexity of the mammalian

\footnotetext{
Received Mar. 10, 1986; revised Aug. 6, 1986; accepted Aug. 8, 1986.

Supported by NIH Grants NS-07118 and NS-21571 to M.M.O.; NS-18361 to S.T.B.; NS-18975 to I.G.M.; and NS-14900 and NS-15731 to R.J.L. The authors wish to thank Vivian Pocek, Shirley Ricketts, and Diane Filsinger for their excellent technical assistance.

Correspondence should be addressed to Dr. M. Oblinger at her present address: Department of Biological Chemistry and Structure, The Chicago Medical School, North Chicago, IL 60064.

a Present address: Department of Cell Biology, University of Texas, Health Science Center, Dallas, TX 75235.

Copyright (C) 1987 Society for Neuroscience $0270-6474 / 87 / 020453-10 \$ 02.00 / 0$
}

nervous system presents an obstacle to studies that aim to characterize biochemical distinctions between different neurons. For example, characterization of the basic protein composition of neurons in various dissected brain regions by gel electrophoresis is complicated by the presence of non-neuronal cells in the samples. Attempts to overcome this problem have included the use of cell-specific probes. In fact, recent studies employing monoclonal antibodies or molecular biological probes have provided substantial evidence for molecular differentiation among neurons (Barnstable, 1980; Villiamy et al., 1981; Schachncr, 1982; Hendry et al., 1984; Bloom et al., 1985). Another very powerful method for exploring cytotypic differences in the nervous system was made available over a decade ago when the processes of axonal transport were identified and characterization was begun (reviewed in Grafstein and Forman, 1980). At present, however, the paradigm of comparing the biochemical composition of axonally transported material in different types of neurons has not been fully exploited in cell biological research.

Virtually all axonal proteins are supplied by axonal transport from the synthetic centers in the cell body. Thus, the composition of different types of axons can be assessed by radioactively labeling proteins synthesized by particular neurons and comparing the axonally transported proteins at some distance from the cell bodies at later times. The method provides several advantages to studies of cytotypic differentiation. One advantage is that axonal proteins in selected populations of axons can be studied without confusion from glial proteins or proteins in other unlabeled cells. In addition, proteins that comprise different structures within axons can be segregated by their rate of transport. For example, proteins of membranous organelles move in the fast component of axonal transport, while cytoskeletal proteins and constituents of the cytomatrix move with the 2 slow components of transport (reviewed in Grafstein and Forman, 1980; Levine and Willard, 1980; Tytell et al., 1981; Brady and Lasek, 1982; Lasek et al., 1984). Another advantage of the paradigm is that a large number of proteins can be examined simultaneously and many comparisons between different classes of neurons can be made without the development of specific probes.

Initial analyses of the biochemical composition of axonally transported material focused on the fast component of axonal transport. Not surprisingly, differences between transmitter-related substances-either the transmitters themselves or the enzymes involved in synthesis and metabolism of neurotransmitters - have been documented in different neurons (reviewed in Grafstein and Forman, 1980). By contrast, more general biochemical comparisons of various neurons, based on electrophoretic or chromatographic analyses of proteins associated with 
the fast component, did not reveal many differences. In fact, a number of comparisons of rapidly transported proteins in a variety of neuronal types indicated that most major proteins are common to all neurons (Barker et al., 1977; Bisby, 1977; Padilla et al., 1979; Stone and Wilson, 1979). Only a few specific differences among fast-component proteins in different neurons have been documented (Black and Lasek, 1978).

Most of the material moving in axonal transport is associated with the slow components SCa and SCb (Lasek et al., 1984). In light of this, it is surprising that relatively little attention has been paid to differences in the composition of the slow components in various neuronal populations. Such comparisons could be especially informative because, unlike the situation with the fast component, many of the proteins associated with slow axonal transport have been identified. These include the cytoskeletal proteins and elements of the cytoplasmic matrix, such as certain metabolic enzymes (Hoffman and Lasek, 1975; Lasek and Hoffman, 1976; Black and Lasek, 1980; Brady and Lasek, 1981, 1982; Tytell et al., 1981). Thus, quantitative comparisons of slow transport can provide information about both the properties of the axonal cytoskeleton and the metabolic state of particular sets of neurons.

While a comprehensive comparative study of the protein composition of the slow components in different axonal types in rat had not been previously made, a survey of published data from several types of axons suggests that important compositional as well as kinetic differences exist (Lasek and Hoffman, 1976; Mori et al., 1979; Black and Lasek, 1980; McQuarrie et al., 1980, 1986; Tytell et al., 1981; Lasek et al., 1983a; McQuarrie, 1983; Wujek and Lasek, 1983). In the present study, we addressed this issue directly and report here the results of qualitative and quantitative analyses of the composition of $\mathrm{SCa}$ and $\mathrm{SCb}$ in 3 types of neurons: retinal ganglion cells, dorsal root ganglion (DRG) cells, and ventral motor neurons (VMN) in rat. The peaks of $\mathrm{SCa}$ and $\mathrm{SCb}$ were chosen as representative of each slow-component complex, and high-resolution, 2-dimensional polyacrylamide gel electrophoresis (2D-PAGE) was used to analyze the protein composition of the peaks. The relative amounts of several identified proteins in both $\mathrm{SCa}$ and $\mathrm{SCb}$ were determined. A number of striking biochemical differences were noted and some of these could be related to structural or physiological differences between the 3 types of neurons.

\section{Materials and Methods}

Radiolabeling axonal proteins in vivo. Adult male Sprague-Dawley rats (250-350 gm) were used in all experiments. Slowly transported proteins were radiolabeled during synthesis in the neuron cell bodies with $L-{ }^{35} S$ methionine (New England Nuclear, Boston, MA). In all cases, the labeled methionine was lyophilized and resuspended to desired concentrations in distilled water just prior to use. For all surgical procedures, animals were anesthetized by intraperitoneal injection of sodium pentobarbital $(27 \mathrm{mg} / \mathrm{kg})$ and chloral hydrate $(128 \mathrm{mg} / \mathrm{kg})$. To label sensory axons in the sciatic nerve, the fifth lumbar (L5) DRG was exposed by a partial laminectomy and $2 \mu \mathrm{l}$ of ${ }^{35} S$-methionine $(250 \mu \mathrm{Ci} / \mu \mathrm{l})$ was injected into the midpoint of the DRG using a glass micropipette. Axons in the sciatic nerve arising from lumbar VMN were labeled by microinjection of $1 \mu \mathrm{l}$ of isotope $(250 \mu \mathrm{Ci} / \mu \mathrm{l})$ into each of $4-5$ sites of the ventral horn of the L4-L5 spinal cord after a laminectomy. Axons of retinal ganglion cells in the optic nerve $(\mathrm{ON})$ were labeled by microinjection of $5 \mu \mathrm{l}$ of isotope $(100 \mu \mathrm{Ci} / \mu \mathrm{l})$ into the vitreous body of the eye.

At scheduled times after injection, animals were killed by decapitation and the appropriate labeled nerve system was removed from each animal and rapidly frozen. Frozen nerves were cut into $2 \mathrm{~mm}$ pieces using a Mickle gel slicer (Brinkmann Instruments) homogenized in $200 \mu \mathrm{l}$ of SUB $(0.5 \%$ SDS, $8 \mathrm{~m}$ urea, $2 \%$ beta-mercaptoethanol) and centrifuged
Table 1. Experimental conditions and considerations for obtaining labeled SCa and SCb proteins in 3 axonal systems

\begin{tabular}{llll} 
& $\begin{array}{l}\text { Average trans- } \\
\text { port rate } \\
(\mathrm{mm} / \mathrm{d})\end{array}$ & $\begin{array}{l}\text { Injection-death } \\
\text { interval (d) }\end{array}$ & $\begin{array}{l}\text { Nerve seg- } \\
\text { ments used } \\
\text { for PAGE } \\
\text { (mm from } \\
\text { infection) }\end{array}$ \\
\hline Neuron type & & & \\
SCa & $0.1-0.3$ & $40-42$ & $6-12$ \\
ON & $1.0-1.5$ & 21 & $18-28$ \\
VMN & & 28 & $26-36$ \\
DRG & $1.0-1.5$ & 21 & $18-28$ \\
SCb & & 28 & $26-36$ \\
ON & 2 & & $8-14$ \\
VMN & 4 & $6-7$ & $20-30$ \\
DRG & 4 & 6 & $24-34$ \\
& & 6 & $20-30$ \\
& & 7 & $24-34$ \\
\hline
\end{tabular}

at $17,000 \times g$ for $15 \mathrm{~min}$ into pellet-insoluble material. A $10 \mu \mathrm{l}$ aliquot of each sample supernatant was counted in a liquid scintillation counter to determine the radioactivity. This procedure effectively solubilized all labeled axonal proteins because radioactivity measurements of pellets from the low-speed centrifugation that removed insoluble material from samples were not above background in any experiment.

In this study, we chose to analyze the protein composition of the peaks of $\mathrm{SCa}$ and $\mathrm{SCb}$ as representative of the composition of each slowcomponent wave. A number of previous studies had defined the transport kinetics of $S C a$ and $S C b$ in DRG, VMN, and optic nerve (ON) axons in rat (Hoffman and Lasek, 1975; Mori et al., 1979; Brady and Lasek, 1982; Lasek et al., 1983b; Wujek and Lasek, 1983; McQuarrie et al., 1986) and this information was used to select the injection-death intervals in the present study. Table 1 summarizes the conditions used in harvesting $\mathrm{SCa}$ and $\mathrm{SCb}$ proteins. For each of the neuronal systems, the survival times (from labeling the cell bodies to killing the animals and harvesting the axons) were appropriately adjusted to permit the peak of $\mathrm{SCa}$ or $\mathrm{SCb}$ to move comparable distances from the injection sites. For example, $\mathrm{SCb}$ proteins typically were obtained from VMN or DRG axons located $24-34 \mathrm{~mm}$ from the respective injection sites $7 \mathrm{~d}$ after injection, while SCa proteins were obtained from axons $26-36 \mathrm{~mm}$ distal to the spinal cord (VMN) or ganglion (DRG) in animals killed 4 weeks after injection. For ON axons, a 40-42 d interval was required to allow the peak of SCa to advance 6-12 mm into the nerve, while a $6 \mathrm{~d}$ interval was optimal for obtaining SCb from axons located 8-14 $\mathrm{mm}$ from the eye. Note that both different times and different segments of axons were required for comparing proteins transported with the peak of $\mathrm{SCa}$ or $\mathrm{SCb}$ in the 3 different systems because of differences in the rates of slow axonal transport in these systems. The actual location of the labeling peak in each nerve was determined by liquid scintillation counting, and sample(s) containing peak radioactivity associated with $\mathrm{SCa}$ or $\mathrm{SCb}$ were prepared for gel electrophoresis. For each type of axonal system, 8-13 experimental samples were analyzed for $\mathrm{SCa}$ and $\mathrm{SCb}$.

Gel electrophoresis and detection of labeled proteins. Samples were subjected to 2D-PAGE (O'Farrell, 1975). Prior to isoelectric focusing, samples were mixed with equal volumes of lysis buffer $(8 \%$ Triton X-100, 4\% ampholines, $\mathrm{pH}$ 5-7 (LKB Instruments), 1\% ampholines, pH $3.5-10,5 \%$ beta-mercaptocthanol, $9 \mathrm{~m}$ urca). Isoelectric focusing gels were electrophoresed for $7000 \mathrm{~V} \mathrm{hr}$. Isoelectric points were determined by measuring the $\mathrm{pH}$ of $1 \mathrm{~cm}$ pieces of a tube gel that was included in each run as a standard. For the second dimension, gels were removed from the tubes, loaded onto slab gels containing a 6-17.5\% gradient of polyacrylamide with a $4 \%$ stacking gel, and electrophoresed at $10 \mathrm{~W} / \mathrm{gel}$ using Laemmli (1970) buffer. After completion of electrophoresis, the gels were stained with $0.1 \%$ Coomassie blue, destained, and fluorographs were prepared to visualize labeled proteins (Bonner and Laskey, 1974). In brief, gels were dehydrated with dimethyl sulfoxide (DMSO), impregnated with 2,5-diphenyloxazole/DMSO (New England Nuclear), 

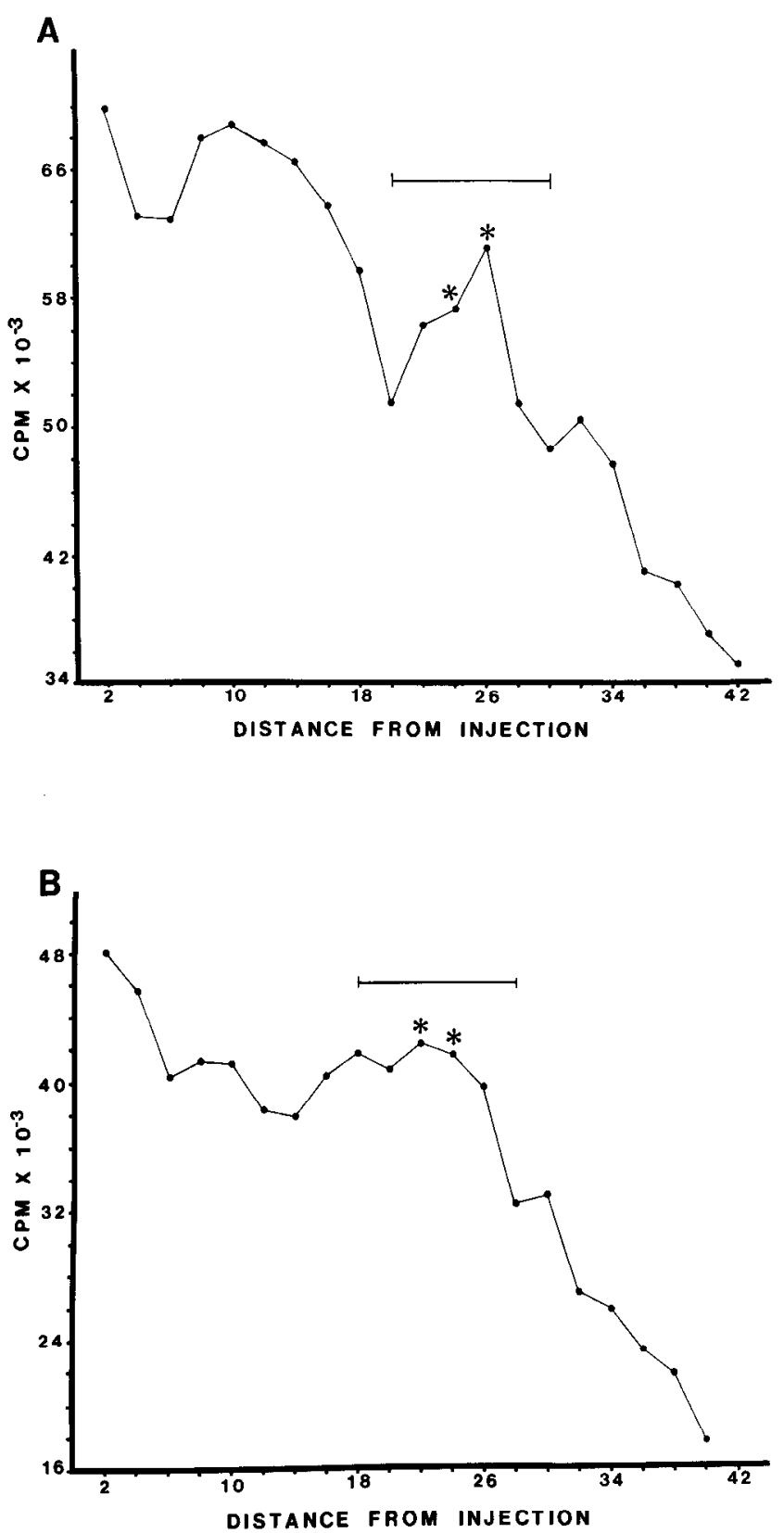

Figure 1. Transport of slow-component proteins in DRG axons. A, Total radioactivity (cpm) in successive $2 \mathrm{~mm}$ segments of the sciatic nerve $6 \mathrm{~d}$ after labeling the L5 DRG with $0.5 \mathrm{mCi}$ of ${ }^{35} \mathrm{~S}$-methionine is plotted as a function of distance from the ganglion. The typical location of the $\mathrm{SCb}$ peak over several experiments is indicated by the horizontal bar and the samples selected for 2D gel analysis in a particular experiment are indicated by asterisks. The position of the $\mathrm{SCb}$ peak is consistent with a transport rate of about $4 \mathrm{~mm} / \mathrm{d}$ in DRG axons. $B$, Typical location of the SCa peak in the sciatic nerve $21 \mathrm{~d}$ after labeling the L5 DRG is indicated by the horizontal bar. Asterisks indicate samples used for gel analysis. The location of the SCa labeling peak is consistent with a transport rate of $1 \mathrm{~mm} / \mathrm{d}$.

rehydrated, and dried between dialysis membranes under vacuum. Dried gels were incubated with preflashed Kodak XAR -5 film at $-70^{\circ} \mathrm{C}$ for 1-4 weeks.

Criteria for protein identification. Many of the slowly transported proteins examined in this study had been previously identified in studies by this or other laboratories. These include tubulin, actin, neurofilament proteins, and fodrin (spectrin), which were identified in axonal transport studies using a variety of methodologies, including comigration with purified proteins on 2D-PAGE, peptide mapping, antibody staining,
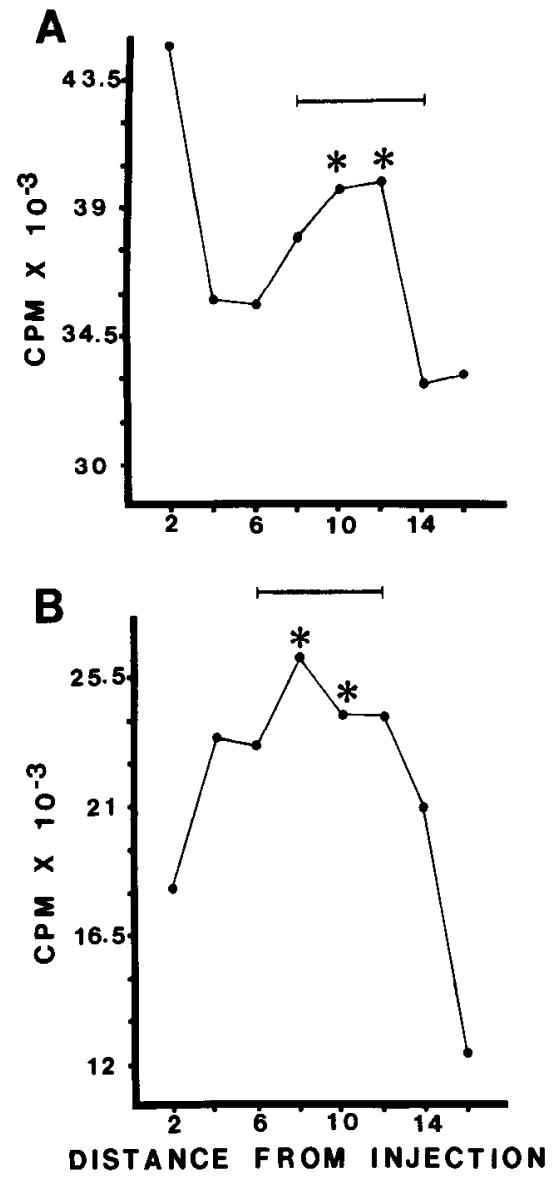

Figure 2. Transport of slow-component proteins in $\mathrm{ON}$ axons. $A$, Radioactivity (cpm) in successive $2 \mathrm{~mm}$ segments of the optic nerve $6 \mathrm{~d}$ after injecting $0.5 \mathrm{mCi}$ of ${ }^{35} S$-methionine into the vitreous body. The average location of the $\mathrm{SCb}$ peak over several experiments is indicated by the horizontal bar and the samples used for 2D-PAGE in the particular experiment illustrated are indicated by asterisks. The $\mathrm{SCb}$ rate in ON axons was about $2 \mathrm{~mm} / \mathrm{d}$. $B$, The typical position of the SCa peak in $\mathrm{ON}$ axons $42 \mathrm{~d}$ after labeling the eye is indicated by the horizontal bar; asterisks indicate samples used for 2D-PAGE in the representative experiment graphed. The estimated $\mathrm{SCa}$ rate in $\mathrm{ON}$ axons was $0.1-0.3$ $\mathrm{mm} / \mathrm{d}$.

and other criteria (Hoffman and Lasek, 1975; Black and Lasek, 1979, 1980; Willard et al., 1979; Levine and Willard, 1980; Tytell et al., 1981; Brady et al., 1984; Lasek et al., 1984; Tashiro et al., 1984). Specific details on the identification of microtubule-associated proteins, nervespecific enolase, and creatine phosphokinase in axonal transport have also been described previously (Brady and Lasek, 1981; Tytell et al., 1984). In the present report, the proteins named were similar in molecular weight, isoelectric point, and spot morphology to previously identified proteins of slow transport.

Quantitation of axonally transported proteins. Fluorographs were used to locate the positions of major labeled polypeptides on the gels. These spots were excised using a scalpel, and solubilized by incubation in 0.75 $\mathrm{ml}$ of $30 \%$ hydrogen peroxide for $48 \mathrm{hr}$ at $60^{\circ} \mathrm{C}$. Radioactivity was measured by liquid scintillation counting, using Formula 963 (New England Nuclear) as the scintillant. Counts were corrected for quenching, background, and isotope decay and converted to disintegrations per minute (dpm). For each nerve system, 8-13 gels for each SCa and SCb were analyzed. Since in vivo methods of labeling proteins by microinjecting isotope into neuronal regions result in variability in the specific activity of labeling, it is necessary to standardize data from different experiments. We found that the most reliable method of normalizing data was by using ratios. Specifically, the same protein spots were excised from all $2 \mathrm{D}$ gels in a given condition (for example, $\mathrm{SCb}$ from $\mathrm{DRG}$ axons). The combined radioactivity of these proteins in each gel was defined as $100 \%$, and the percentage of this total accounted for by each 

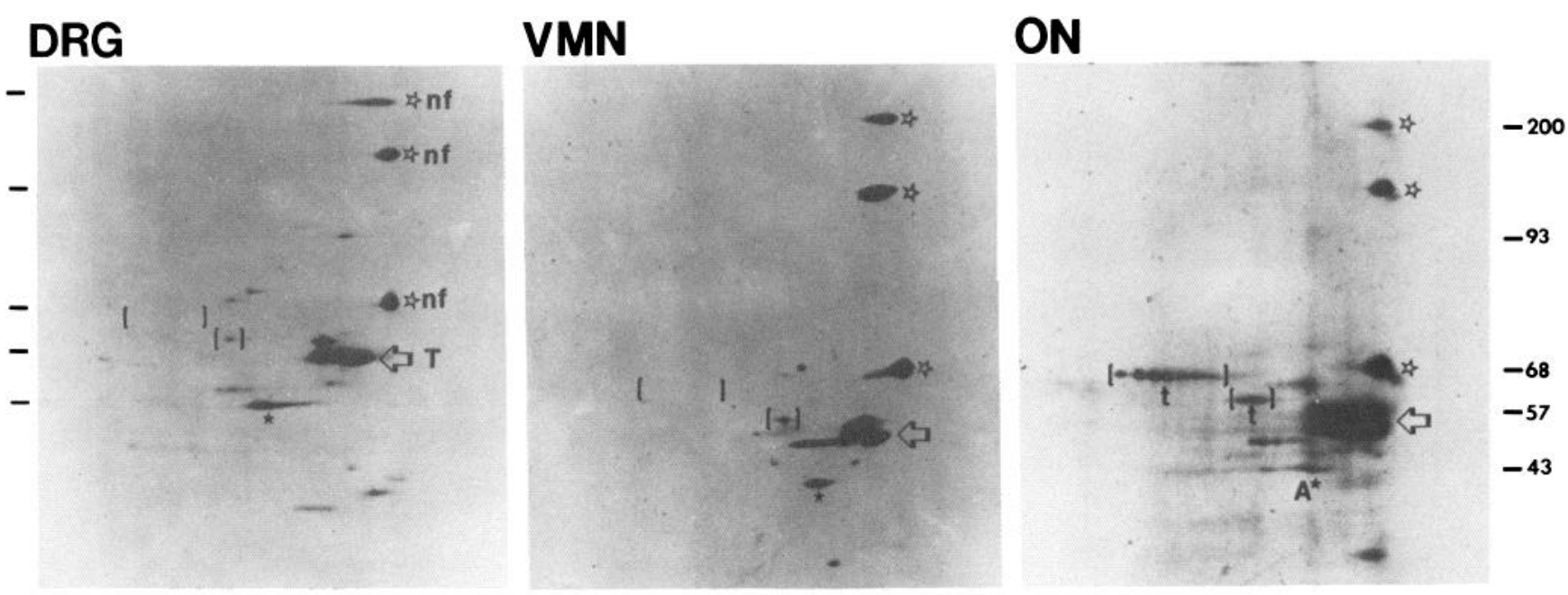

Figure 3. Fluorographs of 2D-PAGE of ${ }^{35} S$-methionine-labeled proteins associated with SCa in 3 neuronal systems. The major proteins in SCa from axons of dorsal root ganglion $(D R G)$ cells, ventral motor neurons $(V M N)$ and optic nerve $(O N)$ are presented. The samples represent 2 mm sections of nerve located at the peak of the SCa wave in each system; details on the injection-death intervals and distance along the nerves used are described in the text. The positions of major structural proteins are indicated: 3 neurofilament proteins ( $n f)$, open stars; tubulin proteins ( $T$ ), open arrow; actin $(A)$, filled star, microtubule-associated proteins $(t)$, parentheses. Molecular-weight standards $(\mathrm{kDa})$ are indicated by bars to each side of the figure; the convention of presenting the acidic portion of the gel on the right side is followed.

protein was calculated. Alternatively, the ratio of radioactivity of 1 protein to another's was calculated for each gel (for example, dpm in the $65 \mathrm{kDa}$ microtubule-associated protein/dpm in tubulin). In either case, means from all experiments in a given condition could then be obtained. Where indicated, statistical significance was assessed using Student's $t$ test at the $95 \%$ confidence level.

\section{Results}

\section{Comparison of slow transport rates}

The distribution of slowly transported radioactivity along different nerves generally had a characteristic waveform that could be divided into leading edge, peak, and tail regions (Figs. 1, 2). In Figure 1, labeling patterns of DRG axons at 6 and $21 \mathrm{~d}$ are illustrated. The SCb peak was typically located $20-30 \mathrm{~mm}$ from the DRG $6 \mathrm{~d}$ after labeling (Fig. $1 A$, Table 1 ). This is consistent with previous observations that the rate of $\mathrm{SCb}$ transport in DRG axons is about $4 \mathrm{~mm} / \mathrm{d}$ (Mori et al., 1979; Wujek and Lasek, 1983; Oblinger and Lasek, 1985). Note that a second, slower-moving peak was also apparent in DRG axons at $6 \mathrm{~d}$ (Fig. $1 A$ ); this peak was that of the emerging SCa wave. The SCa peak was more evident in DRG axons at longer injectiondeath intervals, when the faster-moving $\mathrm{SCb}$ wave had moved distally along the axons. For example, in Figure $1 B$, the SCa peak is located $18-28 \mathrm{~mm}$ from the DRG $21 \mathrm{~d}$ after labeling. This is consistent with a transport rate of about $1 \mathrm{~mm} / \mathrm{d}$ for $\mathrm{SCa}$ (Table 1), which had been previously documented in the DRG system (Mori et al., 1979; Lasek et al., 1983a; Wujek and Lasek, 1983; Oblinger and Lasek, 1985).

The 2 examples from DRG axons illustrated in Figure 1 were also representative of labeling profiles obtained from VMN axons. At different injection-death intervals, the peaks of $\mathrm{SCb}$ and $\mathrm{SCa}$ in VMN axons were typically located at distances from the injection sites that corresponded to transport rates of $4 \mathrm{~mm}$ and $1-1.5 \mathrm{~mm} / \mathrm{d}$, respectively. Thus, the present study confirms several previous reports on the rates of transport of the SCa and $\mathrm{SCb}$ peaks in VMN axons in rat (Hoffman and Lasek, 1975; Lasek and Hoffman, 1976; McQuarrie et al., 1980, 1986; Lasek et al., 1983a).
While the apparent rates of transport of the peaks of SCa and $\mathrm{SCb}$ were similar in VMN and DRG axons, both rates were considerably slower in $\mathrm{ON}$ axons. For example, at $6 \mathrm{~d}$ after labeling retinal ganglion cells, a prominent peak of radioactivity was present in the ON 10-12 mm from the back of the eye (Fig. $2 A$ ). This is consistent with a rate of about $2 \mathrm{~mm} / \mathrm{d}$ for the $\mathrm{SCb}$ peak in $\mathrm{ON}$ axons (Table 1). Much longer intervals were required to harvest $\mathrm{SCa}$ from $\mathrm{ON}$ axons. In a typical experiment, the peak of SCa radioactivity was found in the ON $8-10 \mathrm{~mm}$ from the back of the eye $42 \mathrm{~d}$ after injection (Fig. $2 B$ ). Our estimate of the rate of advance of the SCa peak in ON axons was 0.1$0.3 \mathrm{~mm} / \mathrm{d}$ (Table 1). This is consistent with rates reported in previous studies of SCa in rat ON axons (McQuarrie et al., 1980, 1986; Lasek et al., 1983a).

Samples used for gel analysis of the protein composition of $\mathrm{SCa}$ or $\mathrm{SCb}$ were obtained from nerve segments that contained peak labeling associated with the appropriate slow component. The peaks were chosen as representative of each slow-component wave because preliminary experiments indicated that this was a reasonable assumption. In 2 cases where an absolute peak was not readily discernible in the nerves (one $7 \mathrm{~d} \mathrm{VMN}$ and one $7 \mathrm{~d}$ DRG experiment), samples from 1-2 segments located at distances that typically contained peaks in other experiments at similar time points were used for 2D-PAGE (Table 1).

\section{Comparison of SCa proteins using $2 D-P A G E$}

Fluorographs of $2 \mathrm{D}$ gels that resolved the polypeptides transported with the peak of the SCa wave of transport in DRG, $\mathrm{VMN}$, and $\mathrm{ON}$ axons are presented in Figure 3. The protein composition of SCa was characteristically simple and the major proteins were similar in each of the 3 types of neuron. The predominant proteins were the neurofilament subunits at 200 , 145 , and $68 \mathrm{kDa}$ and the tubulins. Some minor variations in the spot morphology of tubulin were noted between neurons (Fig. 3). The fluorographs in Figure 3 were incubated to provide comparable exposures of the labeled neurofilament proteins in the 3 types of axons. By visual examination, it was apparent that greater amounts of labeled tubulin relative to labeled neu- 


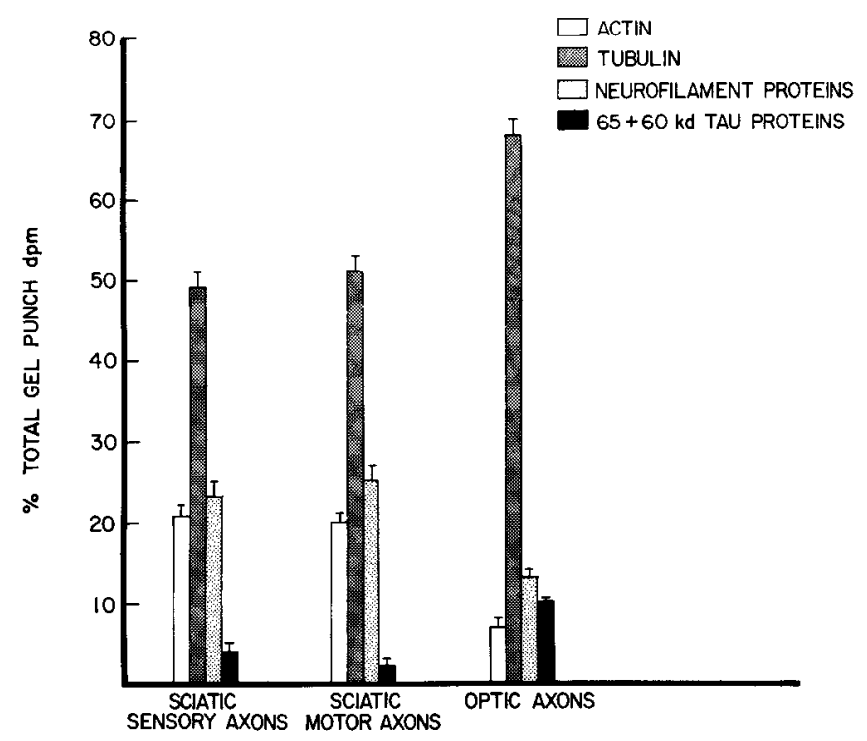

Figure 4. Quantitation of radioactivity distributions among the major $\mathrm{SCa}$ proteins. Using fluorographs as guides, specified proteins were excised from gels, solubilized, and the radioactivity determined. The counts were corrected for background, quenching, efficiency, and isotope decay. The SCa gel punch included all of the proteins marked on the fluorographs shown in Figure 1; data for neurofilament proteins represent the combined 3 subunits. For each type of axon, 9-12 2D gels were analyzed. The total radioactivity from all spots from a given gel was defined as $100 \%$ and the percentage of this total accounted for by each particular protein was calculated. Plotted bars, means \pm SEM.

rofilament protein were present at the $\mathrm{SCa}$ peak in $\mathrm{ON}$ axons than in either DRG or VMN axons. This was also apparent when gels were loaded with equal amounts of total radioactive protein and the fluorographs were exposed for identical periods of time (not shown). Thus, comparison of SCa in the 3 systems indicated that $\mathrm{ON}$ axons contained relatively less neurofilament protein than tubulin, as compared to VMN or DRG axons. In addition to neurofilament protein and tubulin, significant amounts of labeled actin were found at the SCa peak in VMN and DRG axons (Fig. 3). Substantially less labeled actin was present at the SCa peak in ON axons (Fig. 3).

Examination of fluorographs revealed 2 minor SCa proteins at 65 and $60 \mathrm{kDa}$ which were more abundant in $\mathrm{ON}$ axons than in either DRG or VMN axons (Fig. 3). A recent study of slow transport in the optic nerve identified proteins with similar molecular weights, isoelectric points, and spot morphologies as a type of microtubule-associated protein known as "tau" proteins (Tytcll ct al., 1984). The difference in the amounts of these labeled proteins in VMN and DRG axons, as compared to ON axons, was most noticeable for the $65 \mathrm{kDa}$ protein. In fact, even in heavily overexposed fluorographs, the $65 \mathrm{kDa}$ protein was difficult to visualize in SCa samples from DRG or VMN axons, while it was readily observable in those from ON axons. The multiple spotting of the $65 \mathrm{kDa}$ protein in ON axons was consistently observed (Fig. 3). The $60 \mathrm{kDa}$ species could be found in each type of axon, but was clearly more prevalent at the $\mathrm{SCa}$ peak in ON axons than in either VMN or DRG axons.

\section{Quantitation of labeled SCa proteins}

To quantify the distribution of radioactivity among the various SCa proteins, 8 spots were excised from 2D gels, using fluorographs as guides. These gel pieces were dissolved and the radioactivity in each was measured. The combined radioactivity
Table 2. Comparison of labeled SCa proteins in DRG, VMN, and ON axons ${ }^{a}$

\begin{tabular}{llll} 
& $\begin{array}{l}\mathrm{DRG} \\
(n=9)\end{array}$ & $\begin{array}{l}\mathrm{VMN} \\
(n=12)\end{array}$ & $\begin{array}{l}\text { ON } \\
(n=10)\end{array}$ \\
\hline $\begin{array}{c}\text { Neurofilament } \\
\text { proteins/tubulin } \\
\begin{array}{c}\text { Microtubulc associatcd } \\
\text { proteins/tubulin }\end{array}\end{array}$ & $0.48(0.05)$ & $0.52(0.06)$ & $0.19(0.02)^{b}$ \\
\hline
\end{tabular}

a Proteins were excised from $2 \mathrm{D}$ gels and the radioactivity measured. Mean ratios \pm SDs are presented.

${ }^{b}$ Values significantly different using Student's $t$ test at $p<0.05$.

was defined as $100 \%$ and the percentage of this total accounted for by each protcin was detcrmined. For each system, 9-12 gels were quantified. The following proteins were examined: 3 neurofilament proteins, alpha and beta tubulin, actin, and the 65 and $60 \mathrm{kDa}$ microtubule-associated proteins. Figure 4 illustrates that the distribution of radioactivity among these major SCa proteins was very similar in DRG and VMN axons, but differed significantly in ON axons. Tubulin (alpha and beta combined) accounted for $70 \%$ of the combined radioactivity present in the $8 \mathrm{SCa}$ proteins analyzed in $\mathrm{ON}$ axons, but accounted for only $50 \%$ of this total in DRG and VMN axons (Fig. 4). By contrast, the 3 neurofilament proteins accounted for a significantly larger proportion of the SCa radioactivity in VMN and DRG axons (25\%) than in ON (13\%) axons (Fig. 4). When the neurofilament protein radioactivity was normalized to total labeled $\mathrm{SCa}$ tubulin, it was found that the neurofilament-to-tubulin ratios in VMN and DRG axons were nearly 3-fold greater than the ratio obtained in $\mathrm{ON}$ axons (Table 2).

Differences in the amount of actin found at the SCa peak in the 3 axonal systems were also substantiated by quantitation of 2D gels. Actin accounted for $20 \%$ of the SCa peak radioactivity determinations in VMN and DRG axons, as compared to only $6 \%$ in ON axons (Fig. 4). Another quantitative difference concerned the 65 and $60 \mathrm{kDa}$ proteins. Together, these 2 proteins comprised $10 \%$ of the SCa radioactivity in ON axons but only $2-4 \%$ of the SCa radioactivity in VMN and DRG axons (Fig. 4). When normalized to labeled SCa tubulin, the differences in the amount of labeled microtubule-associated proteins present in the 3 nerve systems were quite apparent (Table 2). The microtubule-associated protein : tubulin ratio in $\mathrm{ON}$ axons was significantly greater than this ratio in either DRG or VMN axons; additionally, this ratio in DRG axons was significantly greater than that in VMN axons (Table 2).

The quantitative differences found between ON, DRG, and VMN axons must be considered as relative and not absolute. At present, it is simply not technically possible to directly and simultaneously measure all of the critical parameters needed to conclude that absolute differences exist. For example, the specific activity of labeling and the turnover or replacement rates of various proteins have not been determined. Furthermore, only a portion of the total amount of matcrial in each axonal system has been analyzed. Also, since the rates of transport differ in ON, DRG, and VMN axons, the total flux of protein through these axons during any given interval of time probably differs. Thus, while we feel that the relative differences in the composition of the SCa peak in the 3 axonal populations are predictive of actual differences between these systems, further assessment of these issues is needed once methods are developed to achieve this. 

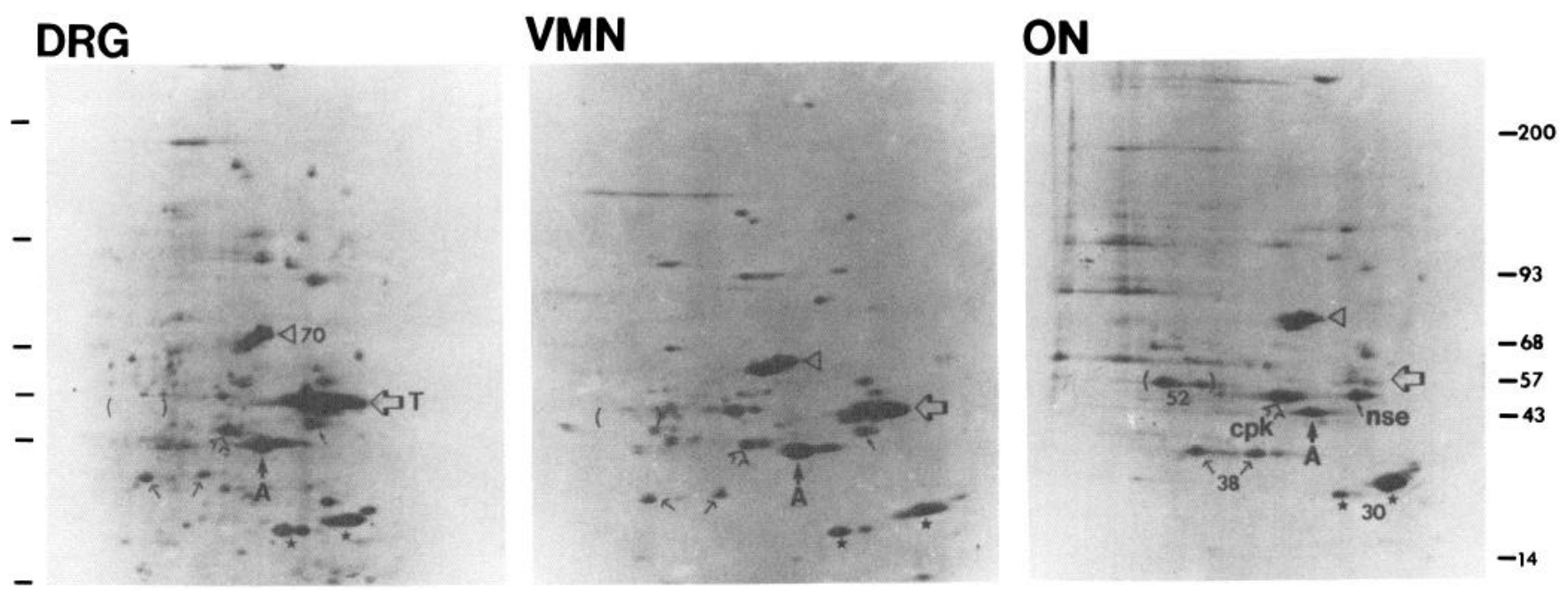

Figure 5. Fluorographs of 2D-PAGE of ${ }^{35} S$-methionine-labeled proteins associated with SCb in 3 neuronal systems. Protocols, see legend to Figure 3. The major labeled SCb protein in DRG and VMN axons, tubulin (T), is marked by a large open arrow. Note the absence of tubulin in the $\mathrm{SCb}$ profile from $O N$ axons. Other major SCb proteins include actin $(A)$, solid arrows; creatine phosphokinase (cpk), small open arrows; nervespecific enolase (nse), small solid arrows. A labeled protein complex at $70 \mathrm{kDa}$ (open triangle), a set of polypeptides at 30-32 kDa (stars), and a doublet at $38 \mathrm{kDa}$ (dotted arrows) are found in each system, but a protein at $52 \mathrm{kDa}$ (parentheses) is prominent in SCb from $O N$ but absent in $D R G$ and $V M N$ axons.

\section{Comparison of SCb proteins with $2 D-P A G E$}

Fluorographs illustrating the constellation of proteins transported with the $\mathrm{SCb}$ peak in DRG, VMN, and ON axons are presented in Figure 5. These protein patterns were considerably more complex than those of SCa and characteristically showed a complete absence of labeled neurofilament protein (Fig. 5). Our analysis focused on the major protein species of $\mathrm{SCb}$. If fluorographs were exposed for longer periods of time than those depicted in Figure 5, well over 100 minor spots could be visualized.

Several polypeptides were major constituents of the $\mathrm{SCb}$ peak in all 3 axonal systems. For example, actin, creatine phosphokinase (CPK), and nerve-specific enolase (NSE) could readily be identified in fluorographs of $2 \mathrm{D}$ gels of $\mathrm{SCb}$ from each system (Fig. 5). In addition, a protein complex at $70 \mathrm{kDa}$, a $30 \mathrm{kDa}$ protein, as well as a protein doublet at $38 \mathrm{kDa}$, were consistently observed as major labeled proteins in SCb in all 3 systems (Fig. 5). Two other proteins that had previously been shown to be major constituents of $\mathrm{SCb}$ were not examined in the present study. Calmodulin, identified in $\mathrm{SCb}$ of guinea pig $\mathrm{ON}$ by Brady et al. (1981) is too acidic to be routinely included in the $\mathrm{pH}$ range of the $2 \mathrm{D}$ gels used. Additionally, clathrin, identified as a major SCb protein by Garner and Lasek (1981), focuses very poorly and inconsistently on $2 \mathrm{D}$ gels.

Generally, the protein composition of $\mathrm{SCb}$ was found to be quite similar in DRG and VMN axons. However, the composition of $\mathrm{SCb}$ in ON axons differed from that in DRG and VMN axons. Of these differences, the most striking were the presence of significant quantities of tubulin in SCb of DRG and VMN axons and the absence of this protein in $\mathrm{SCb}$ in $\mathrm{ON}$ axons (Fig. 5). In fact, in both VMN and DRG axons, tubulin was by far the most abundant labeled $\mathrm{SCb}$ protein. Thus, while tubulin was found in both $\mathrm{SCa}$ and $\mathrm{SCb}$ in VMN and DRG axons, it was present only in $\mathrm{SCa}$ in $\mathrm{ON}$ axons. Another notable difference between the protein compositions of SCb in the 3 types of axons was the presence of a $52 \mathrm{kDa}$ polypeptide in $\mathrm{SCb}$ of $\mathrm{ON}$ axons and the absence of this labeled protein in VMN and DRG axons (Fig. 5). Even heavily overexposed fluorographs of $\mathrm{SCb}$ from VMN and DRG axons did not reveal significant amounts of the $52 \mathrm{kDa}$ protein.

\section{Quantitation of SCb-labeled proteins}

Since $\mathrm{SCb}$ contains a much larger number of proteins than $\mathrm{SCa}$, the problem of quantitatively assessing the amounts of various polypeptide species present in SCb in different axons was relatively difficult. We elected to analyze 8 major SCb proteins. The following polypeptides were excised from gels using fluorographs as guides: actin, NSE, CPK, tubulin, the $70 \mathrm{kDa}$ complex, a $52 \mathrm{kDa}$ protein, a doublet at $38 \mathrm{kDa}$, and a complex at $30-32 \mathrm{kDa}$ (Fig. 5). In the case of 2 proteins that were not present in detectable amounts in all axons (i.e., tubulin from ON axons and the $52 \mathrm{kDa}$ protein from DRG and VMN axons), the region of gel that corresponded to the location where these proteins normally focus was excised. It should be noted that since SCb contains such a large number of polypeptides, most of them minor, the total radioactivity associated with the proteins that were quantified was only a fraction $(30-40 \%)$ of the total SCb radioactivity loaded onto the gels. However, quantifying the radioactivity in these major $\mathrm{SCb}$ proteins was useful in identifying differences in the amounts of these labeled proteins in the 3 neuronal systems. As noted above for SCa proteins, the quantitative differences in the amounts of various $\mathrm{SCb}$ proteins between $\mathrm{ON}, \mathrm{VMN}$, and DRG axons must be considered relative, not absolute, differences.

Figure 6 illustrates the labeling distributions for several of the major $\mathrm{SCb}$ proteins. The data are expressed in a form similar to those in Figure 4. The combined radioactivity in the 8 spots that were excised from 2D gels was defined as $100 \%$ and the percentage of this total accounted for by the radioactivity in each protein was determined. For each type of axon, 8-13 gels were analyzed and mean ratios were calculated. Actin comprised $11-15 \%$ of the measured $\mathrm{SCb}$ radioactivity in each nerve system 


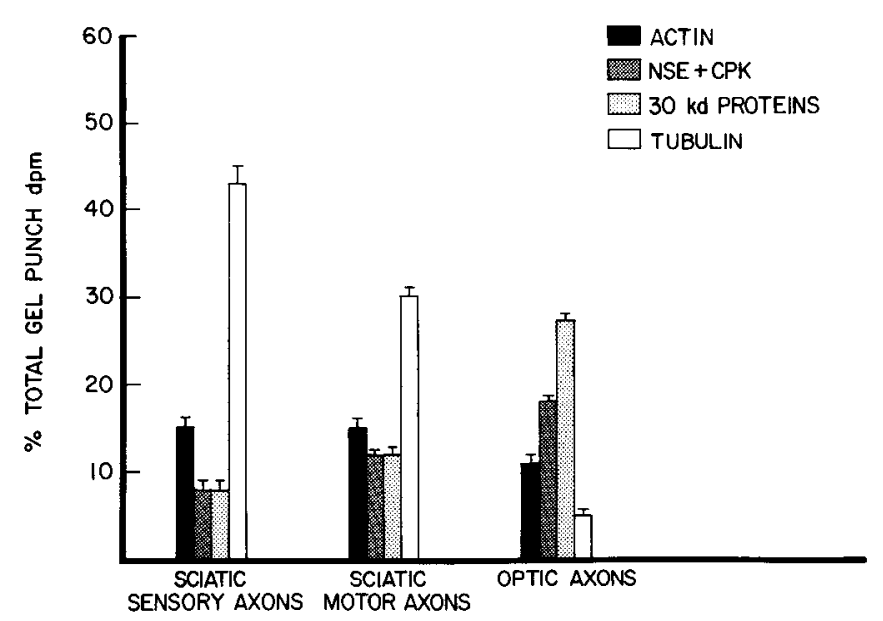

Figure 6. Quantitation of radioactivity distributions among the major $\mathrm{SCb}$ proteins. Using fluorographs as guides, specified proteins were excised from gels, solubilized, and the radioactivity determined. The counts were corrected for background, quenching, efficiency, and isotope decay. For each type of axon, 8-13 2D gels were analyzed. The $\mathrm{SCb}$ gel punch included all 8 proteins (or protein groups) marked on the fluorographs in Figure 5 (but data for all are not plotted). Total radioactivity from all spots from a given gel was defined as $100 \%$; the percentage of this total accounted for by particular proteins was calculated. Plotted bars, means \pm SEM.

(Fig. 6). In both VMN and DRG axons, tubulin was the major labeled protein, accounting for 43 and $30 \%$ of the measured $\mathrm{SCb}$ radioactivity, respectively (Fig. 6). In fact, DRG axons contained significantly more $\mathrm{SCb}$ tubulin than did VMN axons and, obviously, both VMN and DRG axons contained signifcantly more labeled $\mathrm{SCb}$ tubulin than $\mathrm{ON}$ axons (Fig. 6).

Two other differences in the $\mathrm{SCb}$ labeling distributions were notable. One was the prevalence of a complex of lower-molecular-weight proteins $(30-32 \mathrm{kDa})$ in $\mathrm{ON}$ axons compared to either DRG or VMN axons at the SCb peak (Figs. 5, 6). The other difference was the relative predominance of each of 2 metabolic enzymes, NSE and CPK, in SCb in ON axons, as compared to VMN and DRG axons (Figs. 5, 6). In Table 3, the ratios of labeled NSE and CPK to labeled actin in $\mathrm{SCb}$ are presented. The ratios obtained for $\mathrm{ON}$ axons were significantly greater than those from both VMN and DRG axons. In addition, the ratios in VMN axons were significantly larger than those from DRG axons (Table 3).

\section{Discussion}

\section{Axonal transport as a method for delineating cytotypic} differences between neurons

Analysis of the protein composition of the slow components of axonal transport in 3 different axonal populations has revealed a number of striking biochemical differences. We have focused primarily on major, identified proteins of slow transport in the present study, but the method is obviously suitable for comparing a larger number of proteins simultaneously. Because axonal proteins are radioactively labeled, no confusion of neuronal with surrounding non-neuronal (unlabeled) cells occurs and, thus, the information obtained can be related to the composition of various axons. This paradigm provides a useful way of identifying many cytotypic differences between neurons.

The findings of marked differences in slow-component proteins in the 3 axonal systems analyzed are in marked contrast to those of earlier studies that focused on the fast component
Table 3. Comparison of labeled SCb proteins in DRG, VMN, and ON axons ${ }^{a}$

\begin{tabular}{llll} 
& $\begin{array}{l}\text { DRG } \\
(n=8)\end{array}$ & $\begin{array}{l}\text { VMN } \\
(n=8)\end{array}$ & $\begin{array}{l}\text { ON } \\
(n=13)\end{array}$ \\
\hline NSE/actin & $0.23(0.02)$ & $0.41(0.04)^{b}$ & $0.98(0.07)^{b}$ \\
CPK/actin & $0.27(0.04)$ & $0.42(0.02)^{b}$ & $0.79(0.07)^{b}$ \\
\hline
\end{tabular}

a Proteins were excised from $2 \mathrm{D}$ gels and the radioactivity measured. Mean ratios \pm SDs are presented.

${ }^{b}$ Values significantly different using Student's $t$ test at $p<0.05$.

of axonal transport. For example, previous comparisons of the fast component suggested that, besides the transmitter-related substances conveyed in fast transport, most membrane-associated proteins were common to all neurons (Barker et al., 1977; Bishy, 1977; Padilla et al., 1979; Stone and Wilson, 1979; Grafstein and Forman, 1980). Since most previous comparisons of fast transport did not use 2-dimensional gel methods or quantify results, it is possible that minor differences between neuronal systems remained undetected. The fact that major biochemical differences between neurons can be readily identified by comparing the slow components suggests that much of cytotypic differentiation in the nervous system is a function of cytoskeletal and cytomatrix components.

\section{Composition of axonal cytoskeletons and axonal morphology}

The biochemical information obtained using the axonal transport paradigm to study cytoskeletal- and cytomatrix-associated proteins pertains mostly to the largest axons in a given nerve because these axons carry the overwhelming majority of radiolabeled, slowly transported protein (Wujek et al., 1986). For example, electron-microscopic level autoradiography of labeled SCa proteins in DRG axons demonstrated that at least $99 \%$ of the radioactivity was localized over myelinated axons (Wujek et al., 1986). DRG and VMN axons are both myelinated and unmyelinated and range in size from 0.1 to over $13 \mu \mathrm{m}$ (Zenker et al., 1975; Peyronnard and Charton, 1983; Suh et al., 1984). Data reported in the present study are probably relevant only for the large, myelinated fibers in these nerves. On the other hand, mammalian retinal ganglion cell axons are nearly all myelinated and have a relatively uniform and narrow distribution of diameters (Forrester and Peters, 1967; Fukuda et al., 1982). Thus, information obtained from transport studies in the ON is likely to be relevant for most axons in the nerve.

Findings in the present study indicate that VMN and DRG axons convey substantially larger amounts of neurofilament protein in SCa than do ON axons. Additionally, the relative proportion of neurofilament protein to tubulin in $\mathrm{SCa}$ is signifcantly higher in VMN and DRG axons than it is in ON axons. Since neurofilament proteins comprise neurofilaments, and tubulin is the major component of microtubules, the transport data provide indirect evidence that VMN and DRG axons contain relatively more neurofilaments than microtubules compared to $\mathrm{ON}$ axons. A number of lines of evidence indicate that neurofilaments are major determinants of axonal diameter in myelinated axons (reviewed in Lasek et al., 1983b; Hoffman et al., 1984, 1985). Specifically, as axonal diameter increases, the ratio of neurofilaments to microtubules is known to increase (Friede and Samorajski, 1970; Hoffman et al., 1984, 1985). An obvious prediction that might be made from this information is that the average size of myelinated VMN and DRG axons is 
larger than the average size of $\mathrm{ON}$ axons.

In fact, the size differences in axons predicted using the axonal transport method can be substantiated with published morphological data. In the adult rat, myelinated $O N$ axons have an average diameter of about $0.8 \mu \mathrm{m}$ (Forrester and Peters, 1967; Fukuda et al., 1982). Myelinated VMN and DRG axons are considerably larger and have mean diameters around 5-8 $\mu \mathrm{m}$ (Zenker et al., 1975; Suh et al., 1984; Hoffman et al., 1985). While the available technology does not allow us to mathematically determine axonal size from transport data, the preceding example suggests that the relative sizes of other axons that might not have been studied with morphological methods could be approximated using axonal transport data.

\section{Properties of cytoskeletal elements in different axons}

Neurofilament proteins appear to be the only major cytoskeletal proteins associated exclusively with a single rate component (SCa). In contrast, labeled actin is present to some extent at both the $\mathrm{SCa}$ and $\mathrm{SCb}$ peaks in each of the 3 axonal populations examined in this study. Also, significant amounts of labeled tubulin are present at both the $\mathrm{SCa}$ and $\mathrm{SCb}$ peaks in VMN and DRG axons. These observations raise the question of whether the actin and tubulin present in SCa are the same proteins as those present in $\mathrm{SCb}$. The same proteins might be found in both $\mathrm{SCa}$ and $\mathrm{SCb}$ if significant trailing of labeled $\mathrm{SCb}$ proteins occurred. For example, labeled actin in SCa might occur by the deposition of $\mathrm{SCb}$ actin with a relatively stationary structure, such as the plasmalemma. Using 2D-PAGE, we did not detect any obvious and consistent difference between the spot morphologies of the actin from $\mathrm{SCa}$ and $\mathrm{SCb}$ peaks. However, a recent study clearly demonstrated that labeled peaks of actin move with both slow components and that more labeled actin is actually conveyed in $\mathrm{SCa}$ than in $\mathrm{SCb}$ in VMN axons (McQuarrie et al., 1986). Since 2 populations of actin can be defined by their dynamic transport profiles (McQuarrie et al., 1986), as well as by differences in solubility (Morris and Lasek, 1984) and polymer length (Fath, 1985), it is important in future studies to determine whether the actin associated with SCa has different properties or is localized to a different intracellular domain than that associated with $\mathrm{SCb}$.

The observation that tubulin is present in $\mathrm{SCb}$ as well as $\mathrm{SCa}$ in VMN and DRG axons was also reported in several previous studies (Mori et al., 1979; McQuarrie et al., 1980, 1986; McQuarrie, 1983; Lasek et al., 1983a; Wujek and Lasek, 1983; Tashiro et al., 1984; Oblinger and Lasek, 1985). Our present results also confirm that optic axons do not contain $\mathrm{SCb}$ tubulin (Black and Lasck, 1980; Brady and Lasek, 1982; McQuarrie et al., 1980, 1986). While our analysis of 2D gels did not reveal obvious differences in the tubulins from $\mathrm{SCa}$ and $\mathrm{SCb}$, evidence suggesting that $\mathrm{SCa}$ tubulin differs from $\mathrm{SCb}$ tubulin was reported by Tashiro et al. (1984). That study noted differences in the detergent solubility of SCa and $\mathrm{SCb}$ tubulin and apparent differences in the subunit composition of the tubulins in each rate component on gels. The physiological roles and properties of $\mathrm{SCb}$ and $\mathrm{SCa}$ tubulin remain to be elucidated by further study. However, it is of interest that a second type of mammalian CNS axon that has recently been characterized, motor axons of the corticospinal tract, is similar to $\mathrm{ON}$ axons in that it lacks $\mathrm{SCb}$ tubulin (Oblinger, 1984). Results of ongoing studies that further explore the question of whether certain types of axons contain 2 distinct populations of microtubules, while other types do not, will be of great interest.
The 3 axonal populations examined in this study differ in the amounts of microtubule-associated proteins (MAPs) that are conveyed with the SCa peak. Specifically, the ratio of 2 MAPs (60 and $65 \mathrm{kDa}$ ) to tubulin was found to be significantly greater in ON axons than in VMN or DRG axons. These 2 MAPs were previously identified in axonal transport studies in the ON (Tytell et al., 1984) as tau proteins. Immunocytochemical studies using monoclonal antibodies have shown that tau proteins are predominantly localized to axonal regions of neurons (Binder et al., 1985). While the functional significance of differences in the amount of axonally transported MAPs is not known, tau proteins are known to affect the monomer-polymer equilibrium and modify microtubule stability (Cleveland et al., 1977; Raff, 1979; Schliwa et al., 1981). Conceivably, differences in the amounts of axonally transported tau protcin in ON as compared to VMN and DRG axons could influence the properties and dynamics of organization of microtubules in these axons.

\section{Metabolic processes and the axoplasmic matrix in different neurons}

The activity of the nervous system is critically dependent on the availability of ATP, yet little is known about the organization of the enzymes of energy metabolism within neurons. Even less is known about differences in energy metabolism between various types of axons. In this study, we compared the relative amounts of 2 soluble metabolic enzymes transported with the peak of $\mathrm{SCb}$ in ON, VMN, and DRG axons and found that major differences existed. One of the enzymes examined was enolase, which catalyzes the formation of phosphoenolpyruvate in the glycolytic sequence. The second was CPK, a key enzyme involved in phosphagen utilization. CPK is very important in the maintenance of ATP levels in brain and muscle, where creatine phosphate is a main reserve of high-energy phosphate (Lowry et al., 1964). Both CPK and NSE exist as specific isozymes in neuronal tissue (Burger et al., 1964; Friedhoff and Lerner, 1977; Zomzely-Neurath and Keller, 1977).

Brady and Lasek (1981) determined that NSE and CPK are axonally transported over long distances coherently with actin and many other $\mathrm{SCb}$ proteins. This suggests that these proteins are not freely diffusing, but instead are ordered components of the axoplasmic matrix (Brady and Lasek, 1981; Lasek et al., 1984). The nature of the organization of these or other $\mathrm{SCb}$ proteins in the axoplasmic matrix is not known, but it is likely that differences in the composition of this cellular compartment will have functional consequences for the neuron. In the present study we found that $\mathrm{ON}$ axons convey substantially more labeled NSE and CPK compared to actin in SCb than do VMN or DRG axons. With the techniques we employed, it is not possible to conclude that the absolute levels of these enzymes differ in ON, VMN, and DRG axons, but our data suggest that this is the case. Thus, the intriguing possibility that ON, VMN, and DRG axons differ in aspects of energy metabolism arises. Studies that directly test this possibility are needed.

In summary, we have found that a comparison of the protcin composition of axonal transport in different neurons provides a sensitive assay for targeting a number of cytotypic differences between cells. It is possible to obtain detailed information on the biochemical heterogeneity of the cytoskeleton and associated elements in different axons by examining the slow components of axonal transport. Observed biochemical differences can be related to previously identified structural or functional differences between neurons or be used to generate new, testable 
hypotheses about fundamental differences between neurons.

The 3 types of axons examined in this study each have different ontogenies. Dorsal root ganglion cells originate from neural crest, ventral motor neurons arise from caudal regions of the neural tube, and retinal ganglion cells arise from rostral regions of the embryonic brain. In the adult, peripheral DRG axons and VMN axons are major constituents of the peripheral nervous system and innervate sensory receptors and muscle cells, respectively; ON axons make up a CNS pathway and terminate cxclusively on other CNS neurons. Because these 3 types of neurons differ markedly in ontogeny as well as functional specialization in the adult, it is perhaps surprising that so many features of slow transport are similar in DRG and VMN axons, but differ in $\mathrm{ON}$ axons. By examining a larger number of axonal systems in the future, it may be possible to evaluate whether systematic differences in aspects of cytoskeletal or cytomatrix organization exist between various classes of neurons. Such a molecular characterization may provide insight into processes that involve the cytoskeleton and cytomatrix but are differentially effective in different neurons-such as regeneration-or which differentially affect some neurons-such as certain neuropathologies.

\section{References}

Barker, J. L., J. H. Neale, and W. M. Bonner (1977) Slab gel analysis of rapidly transported proteins in the isolated frog nervous system. Brain Res. 124: 191-196.

Barnstable, C. J. (1980) Monoclonal antibodies which recognize different cell types in the rat brain. Nature 286: 231-235.

Binder, L. I., A. Frankfurter, and L. I. Rebhun (1985) The distribution of tau in the mammalian nervous system. J. Cell Biol. 101: 13711378.

Bisby, M. A. (1977) Similar polypeptide composition of fast transported proteins in rat motor and sensory axons. J. Neurobiol. 8: 303314.

Black, M. M., and R. J. Lasek (1978) A difference between the proteins conveyed in the fast component of axonal transport in guinea pig hypoglossal and vagus motor neurons. J. Neurobiol. 9: 433-443.

Black, M. M., and R. J. Lasek (1979) Axonal transport of actin: Slow component $\mathrm{b}$ is the principal source of actin for the axon. Brain Res. 171: 401-413.

Black, M. M., and Lasek, R. J. (1980) Slow components of axonal transport: Two cytoskeletal networks. J. Cell Biol. 86: 616-623.

Bloom, F. E., E. L. F. Battenberg, R. J. Milner, and J. G. Sutcliffe (1985) Immunocytochemical mapping of 1B236, a brain-specific neuronal polypeptide deduced from the sequence of a cloned mRNA. J. Neurosci. 5: 1781-1802.

Bonner, W. M., and R. A. Laskey (1974) A film detection method of tritium-labeled proteins and nucleic acid in polyacrylamide gels. Eur. J. Biochem. 46: 83-88.

Brady, S. T., and Lasek, R. J. (1981) Nerve-specific enolase and creatine phosphokinase in axonal transport: Solublc protcins and the axoplasmic matrix. Cell 23: 515-523.

Brady, S. T., and Lasek, R. J. (1982) Axonal transport: A cell biological method for studying proteins that associate with the cytoskeleton. Methods Cell Biol. 25: 366-398.

Brady, S. T., M. Tytell, K. Heriot, and R. J. Lasek (1981) Axonal transport of calmodulin: A physiologic approach to identification of long-term associations between proteins. J. Cell Biol. 89: 607-614.

Brady, S. T., M. Tytell, and R. J. Lasek (1984) Axonal tubulin and axonal microtubules: Biochemical evidence for cold stability. J. Cell Biol. 99: 1716-1724.

Burger, A., R. Richterich, and H. Aebi (1964) Die heterogenität der kreatin-kinase. Biochem. Z. 339: 305-314.

Cleveland, D. W., S. Y. Hwo, and M. W. Kirschner (1977) Physical and chemical propertics of purificd tau and the role of tau in microtubule assembly. J. Mol. Biol. 116: 2227-2242.

Fath, K. R. (1985) Properties and organization of actin filaments in the squid giant axon. Ph.D. thesis, Case Western Reserve University School of Medicine.
Forrester, J., and A. Peters (1967) Nerve fibers in optic nerve of rat. Nature 214: 245-247.

Friede, R. L., and T. Samorajski (1970) Axon caliber related to neurofilaments and microtubules in sciatic nerve fibers of rat and mice. Anat. Rec. 167: 379-388.

Friedhoff, A. J., and M. H. Lerner (1977) Creatine kinase isozyme associated with synaptosomal membrane and synaptic vesicles. Life Sci. 20: 867-874.

Fukuda, Y., T. Sigimoto, and T. Shirokawa (1982) Strain differences in quantitative analysis of the rat optic nerve. Exp. Neurol. 75:525532.

Garner, J. A., and R. J. Lasek (1981) Clathrin is axonally transported as part of slow component $\mathrm{b}$ : The microfilament complex. J. Cell Biol. 88: $172-178$

Grafstein, B., and D. S. Forman (1980) Intracellular transport in neurons. Physiol. Rev. 60: 1167-1283.

Hendry, S. H. C., S. Hockfield, E. C. Jones, and R. McKay (1984) Monoclonal antibody that identifies subsets of neurons in the central visual system of monkey and cat. Nature 307: 267-269.

Hoffman, P. N., and Lasek, R. J. (1975) The slow component of axonal transport: Identification of major structural polypeptides of the axon and their generality among mammalian neurons. J. Cell Biol. 66: 351-366.

Hoffman, P. N., J. W. Griffin, and D. L. Price (1984) Control of axonal caliber by neurofilament transport. J. Cell Biol. 99: 705-714.

Hoffman, P. N., J. W. Griffin, G. B. Gold, and D. L. Price (1985) Slowing of neurofilament transport and the radial growth of developing nerve fibers. J. Neurosci. 5: 2920-2929.

Laemmli, U. K. (1970) Cleavage of structural proteins during the assembly of the head bacteriophage T4. Nature 227: 680-685.

Lasek, R. J., and P. N. Hoffman (1976) The neuronal cytoskeleton, axonal transport and axonal growth. In Cell Motility, Book C: $\mathrm{Mi}$ crotubules and Related Proteins, R. Goldman, T. Pollard, and J. Rosenbaum, eds., pp. 1021-1051, Cold Spring Harbor Press, New York.

Lasek, R. J., I. G. McQuarrie, and S. T. Brady (1983a) Transport of cytoskeletal and soluble proteins in neurons. In Biological Structures and Coupled Flows, A. Oplatka and M. Balaban, eds., pp. 329-347, Academic, New York.

Lasek, R. J., M. M. Oblinger, and P. F. Drake (1983b) Molecular biology of neuronal geometry: Expression of neurofilament genes influences axonal diameter. Cold Spring Harbor Symp. Quant. Biol. 48: 731-744.

Lasek, R. T., J. A. Garner, and S. T. Brady (1984) Axonal transport of the cytoplasmic matrix. J. Cell Biol. 99: 212S-221S.

Levine, J., and M. Willard (1980) The composition and organization of axonally transported proteins in the retinal ganglion cells of the guinea pig. Brain Res. 194: 137-154.

Lowry, O. H., J. V. Passonneau, F. X. Hasselberger, and D. W. Schultz (1964) Effect of ischemia on known substances and cofactors of the glycolytic pathway in brain. J. Biol. Chem. 239: 18-30.

McQuarrie, I. G. (1983) Role of the axonal cytoskeleton in the regenerating nervous system. In Nerve, Organ and Tissue Regeneration: Research Perspectives, F. J. Seil, ed., pp. 51-88, Academic, New York.

McQuarrie, I. G., S. T. Brady, and R. J. Lasek (1980) Polypeptide composition and kinetics of $\mathrm{SCa}$ and $\mathrm{SCb}$ in sciatic nerve motor axons and optic axons of the rat. Soc. Neurosci. Abstr. 6: 501.

McQuarrie, I. G., S. T. Brady, and R. J. Lasek (1986) Diversity in the axonal transport of structural proteins: Major differences between optic and spinal axons in the rat. J. Neurosci. 6: 1593-1605.

Mori, H., Y. Komiya, and M. Kurokawa (1979) Slowly migrating axonal polypeptides: Inequalities in their rate and amount. J. Cell Biol. 82: 174-184.

Morris, J. R., and R. J. Lasek (1984) Monomer-polymer equilibria in the axon: Direct measurement of tubulin and actin as polymer and monomer in axoplasm. J. Cell Biol. 98: 2064-2076.

Oblinger, M. M. (1984) Slow axonal transport in a CNS motor pathway: The protein composition and kinetics of $\mathrm{SCa}$ and $\mathrm{SCb}$ in hamster corticospinal axons. Soc. Neurosci. Abstr. 10: 1087.

Oblinger, M. M., and R. J. Lasek (1985) Selective regulation of two axonal cytoskeletal networks in dorsal root ganglion cells. In $\mathrm{Neu}$ robiology: Molecular Biological Approaches to Understanding Neuronal Function and Development, P. O'Lague, ed., pp. 135-143, Alan R. Liss, New York.

O'Farrell, P. (1975) High resolution two-dimensional electrophoresis of proteins. J. Biol. Chem. 250: 4007-4024. 
Padilla, S. S., L. J. Roger, A. D. Toews, J. F. Goodrum, and P. Morell (1979) Comparison of proteins transported in different tracts of the central nervous system. Brain Res. 176: 407-411.

Peyronnard, J. M., and L. Charton (1983) Motoneuronal and motor axonal innervation in the rat hindlimb: A comparative study using horseradish peroxidase. Exp. Brain Res. 50: 125-132.

Raff, E. C. (1979) The control of microtubule assembly in vivo. Int. Rev. Cytol. 59: 1-96.

Schachner, M. (1982) Cell type-specific surface antigens in the mammalian nervous system. J. Neurochem. 39: 1-8.

Schliwa, M. V., J. C. Evtenever, J. C. Bulinski, and J. G. Izart (1981) Calcium lability of cytoplasmic microtubules and its modulation by microtubule associated proteins. Proc. Natl. Acad. Sci. USA 78: 1037 1041.

Stone, G. C., and D. L. Wilson (1979) Qualitative analysis of proteins rapidly transported in ventral horn motoneurons and bidirectionally from dorsal root ganglion. J. Neurobiol. 10:1-12.

Suh, Y. S., K. Chung, and R. E. Coggeshall (1984) A study of axonal diameters and areas in lumbosacral roots and nerves in the rat. $J$. Comp. Neurol. 222: 473-481.

Tashiro, T., M. Kurokawa, and Y. Komiya (1984) Two populations of axonally transported tubulin differentiated by their interactions with neurofilaments. J. Neurochem. 43: 1220-1225.

Tytcll, M., M. M. Black, J. A. Garner, and R. J. Lasek (1981) Axonal transport: Each major rate component reflects the movement of distinct macromolecular complexes. Science 214: 170-181.
Tytell, M., S. T. Brady, and R. J. Lasek (1984) Axonal transport of a subclass of tau proteins: Evidence for the regional differentiation of microtubules in neurons. Proc. Natl. Acad. Sci. USA 81: 1570-1574.

Villiamy, T., S. Rathay, and R. Mirsky (1981) Cell-surface antigen distinguishes sensory and autonomic peripheral neurons from central neurons. Nature 291: 481-520.

Willard, M., M. Wiseman, J. Levine, and P. Skene (1979) The axonal transport of actin in rabbit retinal ganglion cells. J. Cell Biol. 81: 581591.

Wujek, J. R., and R. J. Lasek (1983) Correlation of axonal regeneration and slow component $\mathrm{b}$ in two branches of a single axon. J. Neurosci. 3: 243-251.

Wujek, J. R., R. J. Lasek, and P. Gambetti (1986) The amount of slow axonal transport is proportional to the radial dimensions of the axon. J. Neurocytol. 15: 75-83.

Zenker, W., R. Mayr, and J. Gruber (1975) Neurotubules: Different densities in peripheral motor and sensory nerve fibers. Experientia 31: 318-320.

Zomzely-Neurath, C., and A. Keller (1977) The different forms of brain enolase: Isolation, characterization, cell specificity, and physiological significance. In Mechanisms, Regulation, and Special Functions of Protein Synthesis in the Brain, S. Roberts, A. Lajtha, and W. H. Gispen, eds., pp. 279-298, Elsevier/North Holland, Amsterdam. 